\title{
Avaliação histológica do biovidro particulado na reparação de defeito experimental em mandíbula de cães
}

\author{
[Histological evaluation of particulate bioglass in repair of mandible experimental defects in dogs] \\ A.C. Tiomis $^{1}$, A.P.B. Borges ${ }^{2}$, A.P.F. Daibert ${ }^{1}$, T.S. Duarte ${ }^{2}$, K.C.S. Pontes ${ }^{2}$, \\ T.B. Carvalho ${ }^{2}$, E.C. Carlo Reis ${ }^{2 *}$ \\ ${ }^{1}$ Universidade Presidente Antônio Carlos - UNIPAC - Juiz de Fora, MG \\ ${ }^{2}$ Departamento de Veterinária - UFV \\ Av. P.H. Rolfs, s/n \\ 36570-000 - Viçosa, MG
}

\begin{abstract}
RESUMO
Avaliou-se histologicamente o biovidro particulado como substituto ósseo na regeneração de defeitos no osso alveolar da mandíbula, utilizando-se 28 cães adultos, divididos em dois grupos. Foram criados defeitos ósseos na superfície vestibular da mandíbula, entre as raízes mesial e distal do quarto pré-molar direito. No grupo tratado, o defeito foi preenchido com biovidro enquanto no outro, o grupo-controle, o defeito permaneceu sem preenchimento. Aos 8, 14, 21, 42, 60, 90 e 120 dias do pós-operatório, foram coletadas amostras da região da falha óssea de dois animais de cada grupo para a análise histológica sob microscopia de luz. No grupo-controle, observou-se início do processo de reparação óssea aos 14 dias que evoluiu até que, aos 120 dias, não havia mais limite entre as margens do defeito e o novo osso. No grupo tratado, aos oito dias, observou-se a presença de tecido conjuntivo frouxo altamente vascularizado ao redor das partículas de biovidro, até que aos 60 dias o biovidro havia sido totalmente reabsorvido, e o defeito apresentava-se completamente preenchido por osso trabecular. Conclui-se que o biovidro é biocompatível, é osteocondutor e diminui o tempo de reparação do osso alveolar.
\end{abstract}

Palavras-chave: cão, biovidro, substituto ósseo, processo alveolar

\begin{abstract}
By histological analyses, bioglass was evaluated as a bone substitute in the regeneration of alveolar bone defects in mandibles of $28 \mathrm{dogs}$, which were distributed in two groups. Defects were made in the vestibular surface of the mandible between the roots of the right fourth premolar tooth. In treated group, defects were filled with bioglass, while it did not receive any treatment in the other, being used as control. For histological analyses, samples including the bone defect area of two animals per group were collected after 8, 14, 21, 42, 60,90 , and 120 days after surgery. In the control group, bone repair began on the day $14^{\text {th }}$, developing until the day $120^{\text {th }}$, when no limit between the margins of the defect and the new bone existed. In the treated group, at the day eightieth, loose connective tissue highly vascularized around the bioglass particles was observed and on the day $60^{\text {th }}$, bioglass had been totally reabsorbed and the defect was completely filled by trabecular bone. It can be concluded that the bioglass is biocompatible and osteoconductive, and shortens the time needed for alveolar bone repair.
\end{abstract}

Keywords: dog, bioglass, bone substitute, alveolar process

\section{INTRODUÇÃO}

Cerca de $85 \%$ dos cães e gatos com mais de três anos de idade apresentam algum grau de enfermidade periodontal, principal causa da perda do osso alveolar e, consequentemente, de perdas dentárias, que implicam prejuízo das funções de preensão e mastigação dos alimentos (Emily, 1999). Além disso, a reabilitação do osso alveolar perdido é pré-requisito essencial

Recebido em 31 de agosto de 2009

Aceito em 13 de fevereiro de 2010

*Autor para correspondência (corresponding author)

E-mail: emilycarlo@yahoo.com.br 
para a colocação do implante osseointegrado. Os substitutos ósseos são usados com intuito de promover a formação de osso suficiente para prover estabilidade ao implante (Donath et al., 2000).

O material de enxerto ósseo ideal deve ser biocompatível e gradualmente substituído pelo osso neoformado e possuir, preferencialmente, propriedades osteoindutoras e/ou osteocondutoras (Jensen et al., 1996). Além disso, os enxertos ósseos não devem acarretar alterações secundárias ou instabilidade biológica no organismo (Donath et al., 2000).

$\mathrm{O}$ biovidro, material sintético constituído de $\mathrm{SiO}_{2}, \mathrm{Na}_{2} \mathrm{O}, \mathrm{CaO}$ e $\mathrm{P}_{2} \mathrm{O}_{5}$, tem sido considerado uma alternativa viável para a reparação de falhas ósseas (Laurence e Hillier, 2003). Possui grande capacidade de ligação ao osso, o que se deve à sua reatividade química em fluidos fisiológicos, resultando na formação de uma camada de hidroxiapatita, à qual o osso é capaz de se ligar (Shapoff et al., 1997; Stoor et al., 1998). Segundo Turunen et al. (1997), o biovidro é biocompatível, não tóxico e liga-se diretamente ao osso.

Testes in vitro demonstraram que a formação de uma camada de hidroxiapatita na interface se formou com um dia, ao contrário das demais cerâmicas biocompatíveis que demoraram até 30 dias para que o mesmo acontecesse (Yamamuro, 1994). Segundo Hench (1998), diferenças entre o osso normal e o osso neoformado não são notadas quando se utiliza o biovidro.

De acordo com Piattelli et al. (2000), o biovidro apresenta grande capacidade osteocondutora além de alta biocompatibilidade e ausência de interposição de tecido fibroso na interface. Fetner et al. (1994), ao utilizarem o biovidro na maxila de macacos, observaram a formação de material ósseo ao redor das partículas de biovidro não contínuas com o osso, sugerindo as propriedades osteocondutora e osteoindutora do material.

O biovidro particulado é especialmente útil para o tratamento de defeitos ósseos, uma vez que pode ser facilmente adaptado ao formato da falha, além de possuir efeito hemostático e ser de fácil manipulação. Além disso, devido à relação superfície-volume, a capacidade osteocondutiva é aumentada e, como é degradado, funciona como arcabouço temporário para o suporte do crescimento ósseo (Vogel et al., 2001).

Oonish et al. (1999), ao trabalharem com vários tipos de substitutos ósseos, relataram que o uso do biovidro permite proliferação óssea mais rápida quando comparada a outros produtos, o que sugere propriedade osteoindutora, e estimula a rápida proliferação do osso por ativar o controle genético que leva à produção dos fatores de crescimento. Estudos recentes demonstraram que o biovidro promove a migração, replicação e diferenciação de células osteogênicas da medula óssea de humanos (Piattelli et al., 2000; Amaral e Costa, 2002).

Xynos et al. (2001) relataram que o biovidro também pode promover a expressão de genes específicos que afetam a diferenciação de osteoblastos. Os produtos da dissolução do biovidro parecem ter efeito direto na expressão gênica dos osteoblastos humanos, caracterizando o seu efeito osteoindutor.

Em um estudo que comparou hidroxiapatita e biovidro, foi descrito que a velocidade do crescimento de osso ao redor das partículas do biovidro foi mais rápida e que o osso formado era mais denso (Oonishi et al., 1994). Segundo Schepers et al. (1998), a vascularização observada no leito do implante tratado com biovidro foi mais pronunciada do que no sítio controle. Além disso, os defeitos tratados com biovidro continham cerca de duas vezes mais tecido ósseo do que os defeitos controle.

O objetivo do presente trabalho foi estudar as características histológicas do biovidro particulado na regeneração do osso alveolar da mandíbula de cães, analisando os tecidos envolvidos na resposta do organismo a ele, sua biocompatibilidade, osteocondução e o tempo necessário para a formação de novo osso.

\section{MATERIAL E MÉTODOS}

Foram utilizados 28 cães, machos e fêmeas clinicamente sadios, com pesos de 10 a $15 \mathrm{~kg}$, isentos de doença periodontal, provenientes do canil experimental do Departamento de Veterinária da Universidade Federal de Viçosa. Os animais, mantidos em baias individuais, onde 
receberam ração comercial (Selection Special Croc - Royal Canin) duas vezes ao dia e água à vontade, foram divididos aleatoriamente em dois grupos de igual número: um grupo recebeu tratamento com biovidro (grupo tratado), e o outro não, e foi utilizado como controle (grupocontrole).

Após jejum hídrico e sólido de 12 horas, os cães foram sedados com $0,1 \mathrm{mg} / \mathrm{kg}$ de acepromazina (Acepran - Univet - São Paulo) por via endovenosa como medicação pré-anestésica. A anestesia geral foi induzida com propofol na dose de $6 \mathrm{mg} / \mathrm{kg}$ (Eurofarma - São Paulo) também por via endovenosa e mantida com mistura de halotano (Cristália - São Paulo) e oxigênio. Então, a região vestibular da mandíbula direita foi exposta após realização de flap gengival. Foi realizado um defeito de aproximadamente $6 \times 5 \mathrm{~mm}$ entre as raízes mesial e distal do quarto pré-molar, utilizandose broca esférica acoplada a um motor de alta rotação (Aparelhos Odontológicos - Ribeirão Preto).

Nos animais do grupo tratado, o defeito periodontal provocado foi imediatamente preenchido com biovidro particulado (Consul Bioglass - USBiomateriais). A falha óssea provocada nos cães do grupo-controle permaneceu sem tratamento. Em seguida, em todos os animais, o retalho mucoperiosteal foi reposicionado e suturado com pontos contínuos no padrão reverdin de poliglactina 4-0 (Vicryl Ethicon).

Os animais receberam tratamento pós-operatório com antibióticos e anti-inflamatório. As feridas cirúrgicas foram limpas diariamente até a cicatrização. Os animais receberam alimentação pastosa durante duas semanas do pós-operatório.

Nos dias 8, 21 42, 60, 90 e 120 de pósoperatório, foi colhido material da região contendo o defeito de dois animais de cada grupo, por meio do mesmo acesso utilizado para a colocação do implante. Para tal, os animais foram anestesiados como descrito anteriormente. A amostra constou do quarto pré-molar com seu alvéolo, medindo cerca de $1,5 \times 1,0 \times 0,5 \mathrm{~cm}$. Cada amostra foi seccionada no plano transversal e fixada em formalina tamponada $10 \%$ durante cinco dias. Completada a fase da fixação, os fragmentos foram descalcificados em ácido fórmico a 8\% associado ao ácido clorídrico a $8 \%$ durante 30 dias. Posteriormente, os fragmentos foram desidratados em álcool 70 80,90 e $100 \%$ por 24 horas em cada, sendo duas as passagens no álcool absoluto. $\mathrm{O}$ material foi, então, diafanizado em dois banhos de xilol puro, durante 30 a 40 minutos cada.

Os fragmentos receberam dois banhos de parafina de 40 minutos cada, em estufa a $60^{\circ} \mathrm{C}$, foram incluídos em blocos de parafina $\mathrm{e}$ mantidos à temperatura ambiente. A seguir, cortes de cinco micrômetros de espessura foram obtidos em micrótomo e montados em lâmina de vidro. Os fragmentos foram corados pela técnica de hematoxilina - eosina e examinados por microscopia de luz.

Foi realizada análise qualitativa descritiva dos resultados, avaliando-se as reações do organismo ao biovidro e o padrão de regeneração do osso alveolar. Foram comparados os grupos e as datas dentro de cada grupo.

\section{RESULTADOS E DISCUSSÃO}

Nos animais do grupo-controle, observou-se no oitavo dia do pós-operatório início da reabsorção das bordas do defeito com formação de uma matriz óssea e grande proliferação de tecido conjuntivo frouxo na sua superfície (Fig. 1A). O defeito estava preenchido por tecido de granulação pouco vascularizado com maior quantidade de fibras conjuntivas, bastante semelhante ao encontrado por Tampieri et al. (2001) quando trabalhou com coelhos.

No mesmo período, foi possível identificar nos animais do grupo tratado partículas de biovidro circundadas por tecido conjuntivo frouxo altamente vascularizado (Fig. 1D), semelhante ao descrito por Vogel et al. (2001) em coelhos. As partículas de biovidro eram vistas como aglomerados semelhantes a pequenos cristais (Fig. 1D). Nesta observação, ainda não havia sinais de neoformação óssea, nem mesmo nas bordas do defeito. Também não foram observadas células inflamatórias, o que confirma os resultados de Piattelli et al. (2000), quando trabalharam com o biovidro em tíbia de coelhos.

Aos 14 dias, a maior parte da borda do defeito havia sido reabsorvida no grupo-controle e foi 
observada formação de novo tecido ósseo, que se apresentou sob a forma de trabéculas espessas sobre a superfície do defeito (Fig. 1B).

No grupo tratado, aos 14 dias, o quadro era semelhante ao observado no oitavo dia, porém o tecido conjuntivo frouxo ao redor das partículas de biovidro estava mais bem organizado, e foi possível observar feixes de fibras colágenas mais abundantes e espessas, além de maior vascularização. Nas margens do defeito, foi possível identificar finas e esparsas trabéculas ósseas (Fig. 1E), revestidas por grande número de osteoblastos, direcionadas para o centro da falha, sugerindo que o processo de reparação óssea já havia se iniciado e ocorria a partir das bordas, o que confirma os resultados encontrados por Fetner et al. (1994) ao trabalhar em macacos. Piattelli et al. (2000) também relataram que, aos 14 dias, houve formação de pequenas trabéculas ósseas na periferia do defeito.

Aos 21 dias, nos animais do grupo tratado, o biovidro podia ainda ser visualizado no centro do defeito envolvido por tecido conjuntivo frouxo (Fig. 1F), e não mais observado na borda da falha, provavelmente devido à sua absorção, à medida que progrediu o processo de reparação. Nas bordas do defeito, havia projeções de tecido ósseo sob a forma de delgadas trabéculas densamente revestidas por osteoblastos. Algumas trabéculas também eram observadas mais ao centro da falha, demonstrando progresso no processo de reparação óssea do defeito, como o encontrado por Fetner et al. (1994).

Nos animais do grupo-controle, 42 dias após a intervenção cirúrgica, observou-se apenas aumento na formação de osso trabecular na periferia do defeito, com algumas regiões ainda não reabsorvidas. No grupo tratado, no mesmo período, foi possível observar que a região contendo o biovidro envolvido por tecido conjuntivo frouxo era pequena e restrita ao centro da falha. No restante da área do defeito, havia trabéculas ósseas que se apresentavam mais espessas nas bordas (Fig. 1G) e se adelgaçavam à medida que se aproximavam do centro da falha, sugerindo que o processo de reparação óssea progredia da periferia para o centro do defeito. Este achado está de acordo com o de Schmitt et al. (1997) em coelhos, ao citarem que o osso se forma primariamente nas bordas da ferida e progride de forma centrípeta.

No grupo tratado, aos 60 dias, o biovidro não era mais observado, sugerindo que havia sido completamente absorvido. Karatzas et al. (1999), ao utilizarem o biovidro no osso supraalveolar da maxila de macacos, não observaram evidências histológicas de reabsorção das partículas até o $60^{\circ}$ dia do pós-operatório. Isso pode ser justificado por diferentes forças que atuam nestes sítios receptores, acarretando diferenças no metabolismo do ósseo dessas regiões.

Ainda aos 60 dias, no grupo tratado, era evidente em toda a área da falha a presença de trabéculas ósseas que indicavam a reparação completa do defeito (Fig. 1K). Entretanto, ainda era possível a identificação da região da falha. Tal quadro se repetiu aos 90 dias, porém as trabéculas ósseas apresentavam-se mais espessas até que, aos 120 dias, não era possível diferenciar a falha do osso compacto vizinho (Fig. 1L), caracterizando o processo de reparação óssea normal.

No grupo-controle, aos 90 dias, a periferia do defeito foi totalmente preenchida por osso compacto, o que também confirma os resultados de Piattelli et al. (2000). Apenas ao centro da falha pôde-se observar osso trabecular (Fig. 1H). Também no grupo-controle, 120 dias após o procedimento cirúrgico, não havia mais limite entre as margens do defeito e o novo osso formado. Portanto, o defeito estava completamente preenchido com osso lamelar (Fig. 1I). De acordo com o citado anteriormente, o biovidro afetou discretamente o processo de reparação óssea, tornando-o mais rápido, o que pode ser atribuído a sua capacidade osteocondutora.

Em nenhum momento do período de observação, foi verificada a presença de sinais de inflamação ou de reação de corpo estranho associadas ao biovidro, o que confirma resultados de Karatazas et al. (1999) e Vogel et al. (2001). 


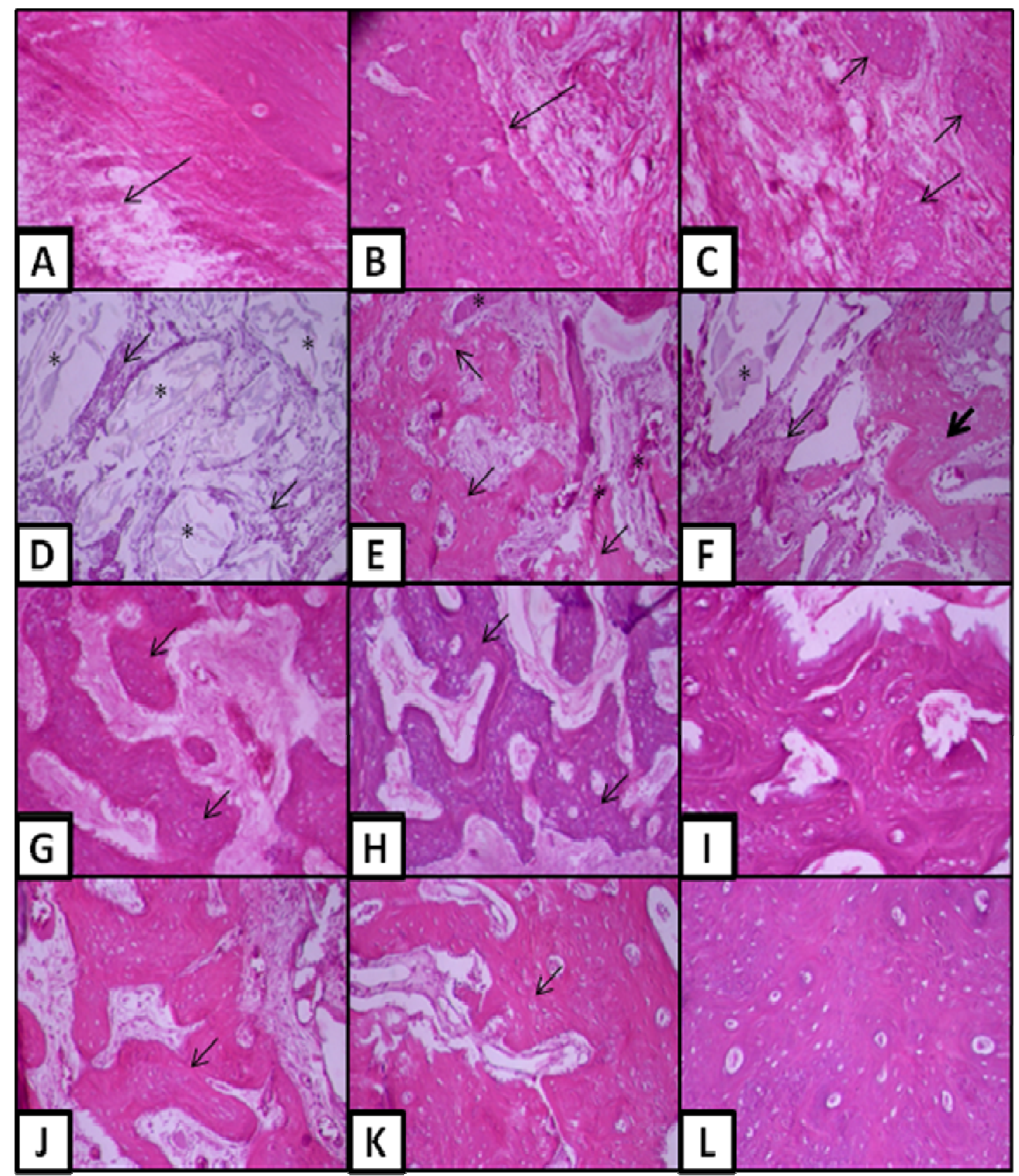

Figura 1. Cortes histológicos da região da falha provocada no osso alveolar de cães, 200X (HE). A, B, C, G, H e I- grupo-controle. D, E, F, J, K e L- grupo tratado. A- 8 dias do pós-cirúrgico. Tecido conjuntivo frouxo na superfície (seta); B- 14 dias do pós-cirúrgico. Área de reabsorção óssea (seta); C- 21 dias do pós-cirúrgico. Trabéculas ósseas (seta); D- 8 dias do pós-cirúrgico. Tecido conjuntivo (setas) envolvendo partículas do biovidro (*); E- 14 dias do pós-cirúrgico. Trabéculas ósseas (seta) e partículas de biovidro (*); F- 21 dias do pós-cirúrgico. Tecido conjuntivo frouxo (seta fina) ao redor de partículas de biovidro (*) e trabéculas ósseas (seta larga); G- 42 dias do pós-cirúrgico. Trabéculas ósseas (seta); H- 90 dias do pós-cirúrgico. Trabéculas ósseas (seta); I- 120 dias do pós-cirúrgico. Osso lamelar. J- 42 dias do póscirúrgico. Trabéculas ósseas (seta); K- 60 dias do pós-cirúrgico. Osso lamelar (seta); L- 120 dias do póscirúrgico. Osso lamelar. 


\section{CONCLUSÕES}

Conclui-se que o biovidro é biocompatível e é possível confirmar sua propriedade osteocondutora, uma vez que serve de suporte para o desenvolvimento de novo osso, tornando o processo de reparação óssea mais rápido. Pode-se afirmar que o biovidro particulado é um substituto ósseo eficiente em cirurgias odontológicas que objetivam a regeneração do osso alveolar.

\section{REFERÊNCIAS BIBLIOGRÁFICAS}

AMARAL, M.; COSTA, M.A. $\mathrm{Si}_{3} \mathrm{~N}_{4}$-bioglass composites stimulate the proliferation of MG63 osteoblast-like cells and support the osteogenic differentiation of human bone marrow cells. Biomaterials, v.23, p. 4897-4906, 2002.

EMILY, P. Periodontia. Enfermidade periodontal. In: ROMÁN, F.S. (Ed). Atlas de odontologia de pequenos animais. São Paulo: Manole, 1999. p.111112.

FETNER, A.E.; HARTIGAN, M.S.; LOW, S.B. Periodontal repair using Perioglas ${ }^{\circledR}$ in nonhuman primates: clinical and histologic observations. Comp. Cont. Educ. Dent., v.15, p. 932-938, 1994

HENCH, L.L. Bioceramics. J. Am. Ceram. Soc., v.81, p.1705-1728, 1998.

JENSEN, S.S.; AABE, M.; PINHOLT, E.M., et al. Tissue reaction and material characteristics of four bone substitutes. Int. J. Oral Maxillof. Implant, v.11, p.55-66, 1996.

KARATZAS, S.; ZAVRAS, A.; GREENSPAN, D. et al. Histologic observations of periodontal wound healing after treatment with Perioglas in non-human primates. Int. J. Periodont. Rest. Dent., v.19, p.489499, 1999.

LAURENCE, P.; HILLIER, I.H. Towards modeling bioactive glasses: quantum chemistry studies of the hydrolysis of some silicate structures. Comput. Mater. Sci., v.28, p.68-75, 2003.

OONISHI, H.; HENCH, L.L.; WILSON, J. et al. Comparative bone growth behavior in granules of bioceramic materials of various sizes. J. Biol. Mater. Res., v.44, p.31-43, 1999.
OONISHI, H.; KUSHITANI, S.; YASUKAWA, E. et al. Bone growth into spaces between 455S bioglass granules. Bioceramics, v.7, p.139-144, 1994.

PIATTELLI, A.; SCARANO, A.; PIATTELLI, M. et al. Bone regeneration using bioglass: an experimental study in rabbit tibia. J. Oral Implant, v.26, p.257-261, 2000.

SCHEPERS E.; BARBIER, L.; DUCHEYNE, P. Implant placement enhanced by bioactive glass particles of narrow size range. Int. J. Oral Maxillof. Implant, v.13, p.655-665, 1998.

SCHMITT, J.M.; BUCK, D.C.; JOH, S. et al. Comparison of porous bone mineral and biologically active glass in critical - sized defects. J. Periodontol., v.68, p.1043-1053, 1997.

SHAPOFF, C.A.; A. LEXANDER, D.C.; CLARK, A.E. Clinical use of a bioactive glass particulate in the treatment of human osseous defects. Compendium, v.18, p.352-363, 1997.

SPIEKERMANN, H.; DONATH, K.; HASSELL, T. et al. Procedimentos cirúrgicos. In: Implantologia. São Paulo: Santos Livraria, 2000. p.130-157.

STOOR, P.; SODERLING, E.; SALONEN, J. Antibacterial effects of a bioactive glass paste on oral microorganisms. Acta Odontol. Scand., v.56, p.161165,1998

TAMPIERI, A.; CELLOTI, G.; SPRIO, S. et al. Porosity-graded hydroxyapatite ceramics to replace natural bone. Biomaterials, v.22, p.1365-1370, 2001.

TURUNEN, T.; PELTOLA, J.; HELENIUS, H. et al. Bioactive glass and calcium carbonate granules as filter material around titanium and bioactive glass implants in the medular space of the rabbit tibia. Clin. Oral Implant. Res., v.8, p.96-102, 1997.

VOGEL, M.; VOIGT, C.; GROSS, U.M. et al. In vivo comparison of bioactive glass particles in rabbits. Biomaterials, v.22, p.357-362, 2001.

XYNOS, I.D.; EDGAR, A.J.; BUTTERY, L.D. et al. Gene-expression profiling of human osteoblasts following treatment with the ionic products of BioglassÒ 45S5 dissolution. J. Biomed. Mater. Res., v.55, p.151-157, 2001.

YAMAMURO, T. Bone bonding behavior and clinical use of A-W glass-ceramic. In: URIST, M.R.; O'CONNOR, B.T.; BURWELL, R.G. (Eds). Bone grafts derivatives and substitutes. Cambridge: Butterworth-Heinemann, 1994. p.245-259. 